

RESEARCH ARTICLE

\title{
Wellbeing Agencies in the High Street: The Rebirth of Primary Health Care?
}

\author{
Geoffrey Meads* \\ Health Sciences Research, Health and Wellbeing Research and Development Group, University of Winchester, \\ Winchester, UK
}

\begin{abstract}
The rapid increase in frontline service outlets offering Wellbeing services offers new opportunities to promote public health. However, driven by both economic and social policies closely linked to the needs for both new business development and cultural integration, the expansion in organisational practices also carries it with some risks to public health. In more market oriented health systems these include possible negative consequences for both the longitudinal care provided through general medical practices and the application of evidence based medicine.

In this context the scoping review draws on indicative findings from fieldwork in two international exemplar sites in the UK and Australia, where the concept of Wellbeing is being embedded, to identify priorities for future health policy and management research. The analysis is framed by the WHO's enduring core principles for Primary Health Care, with the data capture employing an ethnographic approach that includes key informant interviews in Melbourne over a six months period in 2015/16. The findings include an unexpected emphasis on the need for knowledge in respect of the communities of interest and practice forming around novel therapies and interventions that assert public health values.
\end{abstract}

Keywords: Diversity, High street, Primary health care, Social organization, Wellbeing, Wellness.

\section{INTRODUCTION}

In the past the British primary care system has been perceived as more advanced than its Australian counterpart, with the extended general practice team, for example, possessing deeper roots in its communities and a broader remit for service delivery $[1,2]$. However, with an international trend towards more diverse frontline Wellbeing agencies, we are now witnessing what may well be regarded as a reversal of this pecking order. In some countries this century has seen the conventional UK primary medical care model, rooted in uni-professional partnerships, being overtaken by a new mixed economy of frontline services based upon multi-sectoral ownership, with variable results [3, 4]. While such diverse service profiles often characterise poorer countries, especially in southern Africa in the last century, they are now more prominent in Western states as well. This is especially evident in parts of Australia, where the legislative reforms of the 1990s, favouring private health facilities underpinned by taxation triggered co-payments [5], now appear to be firmly embedded.

Between January 2015 and February 2016 this author spent six months working in Melbourne in Victoria, based principally at Monash University. In addition to completing a secondary data analysis of different approaches to community governance [6] funded through higher education agencies, the work included an independent research function. In this advisory role it became readily apparent that the concept of Wellbeing is not only more prominent in both common parlance and professional exchanges in Victoria, but also more visible in terms of the range of agencies associated with its expression in practice. For example, under the heading of 'Wellbeing Agencies', 14 different types

\footnotetext{
* Address correspondence to this author at the University of Winchester, Sparkford Road, Winchester. SO22 4NR. UK; Tel: 00 44 (0)1962 777721; E-mail: Geoffrey.Meads@winchester.ac.uk
} 
of remedial massage were recorded in the data review - from Zenicure to Lavender Massage - plus new alternative clinical specialisms that range from Dental Psychology to Naturopath Iridology. These are still unknown in the shopping centres of the UK; although along with 'Mindfulness', Wellbeing as a policy notion is becoming more influential in the United Kingdom.

It now serves in the UK as a useful shorthand and slogan for significant developments in NHS public health priorities, moving them away from their previously limited focus on secondary care conditions [7]. The emphasis is now on sustainable and transforming 'place-based systems of care' characterised by lifestyles of 'Wellbeing' that eschew excesses of alcohol, sugar, salt, stress and tobacco, and promote the community based prevention of such chronic conditions as diabetes and depression [8 - 10]. The concept of Wellbeing has also gained traction in sectors of the UK economy outside the normal reach of the NHS. In Higher Education, for example, the concept has helped to empower post-1990 universities looking to develop their academic credentials through courses and knowledge exchange for non-medical health care professionals. At the University of Winchester these include arts practitioners and music therapists.

This progressive trend in the UK and its more advanced expression in Australia suggest some scope for transferable learning. The advent of GP -led clinical commissioning groups in the UK has been matched in the past few months by the merger of local Medicare agencies into Primary Health Networks across the Australian federal system. These two organisational developments have comparable population coverage, scope for wealth creation, and include new assertions of public health roles and responsibilities by local authorities and elected city mayors. There is a broad based contextual fit between the two countries, underpinned by a continuous reciprocal exchange of health personnel and policy ideas.

\section{PURPOSE}

In this context the objective of this short scoping review of Wellbeing organisational practices is to outline an agenda for future transferable learning, highlighting both some of the risks and benefits associated with what might be viewed as a modernised form of the primary health care 'pillar', first constructed by the World Health Organisation in its Alma Ata Declaration of 1978 [11]. This emphasised the necessity of cross-sectoral collaboration to ensure universal access to frontline health services, recognising the impracticality of state funding for comprehensive primary health care in many developing countries. The benefits of this approach now are increasingly self-evident for expanding economies in terms of consumer choice and an increasingly diverse supply side. For example, sleep clinics which combine bed sales with interventions designed to promote regular healthy slumber, are routine in several Melbourne suburbs but unheard of as yet in the UK. Such innovations have attractions in terms of their potential for self-help and new investment, and, of course, diversion from overstretched publicly funded health services. However, although they are less apparent, there are risks too in the adoption of these practices, which in Victoria do often claim 'Wellbeing' dividends. In contrast to the attractions, the hazards may be longer term and more profound: for instance, in their impact on general medical practice, and thence on the provision of comprehensive, longitudinal and relationship based health care.

\section{Research Process}

Wellbeing is understood throughout this project as a brand name encompassing those services and social goods which assert claims to the provision and promotion of an increased sense of what Victorians regularly referred to as 'Wellness', through different forms of non-medical physical, psychological and spiritual healing. As a concept Wellbeing remains loosely and variably defined, with flexible interpretations in practice.

Undertaken privately as an independent project the data capture draws on the ethnographic principle of 'social immersion' [12] for this short scoping review. It includes two mini- case studies in the districts of Brighton, Victoria, Australia and Winchester, Hampshire, UK. Data capture was through five months' participant observation as an internal consultant in the two settings, a geographic mapping exercise of service outlets and local documentary searches; and a series of expert informant interviews with five leaders of clinical education in both Melbourne and Hampshire university health care schools. The main topics for these interviews were organisational trends and relationships associated with Wellbeing, and the response of GPs to changes in these. The Topic Guide at Fig. (1) provides the checklist of key trigger questions. Data capture was in the form of structured daily notetaking, shaped and informed by the WHO criteria for primary health care, as set out in the annual reports of 1978 and 2008 [11, 13]. Specifically, as headings, these criteria covered the so called WHO 'pillars' [14] of stakeholder participation, inter-sectoral 
collaboration and equity (particularly of access).

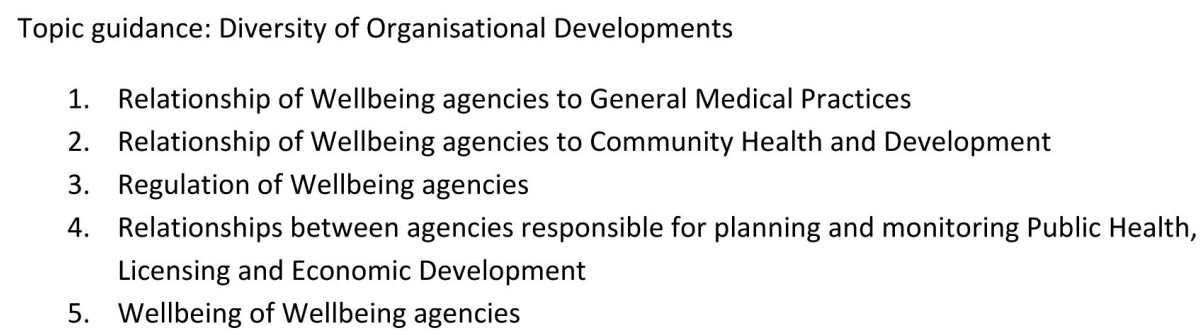

Fig. (1). Wellbeing practices.

\section{Case Studies}

Winchester and Brighton have much in common. Indeed, before the project began an academic colleague from Monash University in Melbourne asserted that visitors from south east England 'feel at home because Brighton is Australia's Winchester'. By this she was referring essentially to social and cultural similarities. Census linked information held in local libraries, and personal observations, soon confirmed that both are relatively affluent districts with pleasant residential neighbourhoods of individual detached houses, a 40 to 45 years median age, and multiple local churches and pavement cafes. Both possess proud histories well captured by outstanding municipal libraries and symbols of civic pride, with statues to the founders, King Alfred in Winchester and Sir Thomas Bent in East Brighton, at the entrance to their high streets. Both have seemingly well integrated ethnic and largely professional class minorities.

Politically both are conservative but with Liberal interludes. And the socio- demographic and cultural similarities are matched by their geographic traits: three main internal suburbs, a hinterland of smaller settlements, scenic golf courses and ready access to sailing and the sea. Of course too, these two locations are not national representatives. The differences are as pronounced as their similarities - Brighton, for example, is much more beach oriented and less than two centuries old - but the parallels are sufficient for them to merit a purposive sample status as a 'convenient' source for what are simply the indicative findings of an exploratory scoping review. As such they satisfy case study criteria for a preliminary project at the identification stage of a scientific research process. In this role these micro-studies may point to possible future topics for primary research, more systematic review and, ultimately, generalizable outcomes $[15,16]$.

So, while St. Andrew's Anglican Church cannot rival the biography of a thousand year old Winchester Cathedral local residents assert that it was deliberately built to be 'of minor cathedral proportions', and the church occupies a comparable central position in Brighton's community networks. And, while generally possessing the characteristics of commuter conurbations, both Brighton and Winchester do not lack for comparable social issues and instances of economic deprivation. For example, there were over 3400 referrals in Winchester to the city's food banks in 2014 [17], while in Brighton increases in unemployment related incidents led to a daily police presence on its railway station platforms at the same time. The hundreds of recent Polish immigrants now resident in Winchester have counterparts over the past decade from China and Sri Lanka in Brighton.

Brighton and Winchester are where local people, and not inconsiderable number of domestic visitors and foreign tourists, shop. Both have attractive high streets in such constituent localities as Bishops Waltham and East Brighton, with restaurants, home grown fruit and farm produce, individual boutiques, banks and the smarter national chain stores present in abundance. And, largely unnoticed outside the mega-cities in their progression over the past decade [18], here as elsewhere, health and wellbeing service outlets have grown, alongside hospitality, to become as prominent as fast food outlets $[19,20]$. 
The profiles of Bishops Waltham High Street in the Winchester District and East Brighton's Bay Street in the municipality governing Bayside District- the equivalent main road - highlight this development. Both are at the heart of their neighbourhood communities, straight roads with speed restrictions, sleeping policemen, one hour free parking limits and c. 800 metres long. Both are eight miles from the city centre, with neighbourhood populations of around 9000 , of which 1 in 10 hail from abroad. Bishops Waltham is more rural and inland, but otherwise they could almost appear interchangeable.

Bishops Waltham has 72 shops and service outlets in the High Street and its adjacent environs. Nine of these provide health care: two opticians, two community pharmacists, an osteopath, a dermatology and beauty clinic, a new multi-purpose 'Healthspace' and two offering care facilities. As a 'Health and Wellbeing' sector the total comes second only to 'Hospitality', which has 15 sites including eight cafes. Next in line are property and estate agents, and hairdressing, with seven and six shops respectively.

In East Brighton, as might be expected, given the country's legislative lead on sanctioning private health care developments, the profile is more aligned in favour of alternative service outlets offering health and health care interventions associated with the promotion of Wellbeing. In 2014/15 there were 88 shops on Bay Street, including 21 cafes, bars and restaurants. But by 2014 there were also 30 service outlets supplying Wellbeing services; and ten of these explicitly claimed to promote 'Holistic Health': traditionally the sovereign property of GPs' general medical services. Amongst these are claims to 'optimal combinations of herbal and scientific technology', 'body and soul' care, fitness regimes which 'extend and advance your life', and massage for 'peak performance'. Massage itself is the most frequently cited intervention.

In both locations the volume of health and health care facilities is still increasing. In Bishops Waltham for example, both 'Healthspace' and the 'foot treatment' centre offered in one of the two shoe shops were established in 2014. In East Brighton, since 2013, three alternative Pilates programmes have operated across five buildings in a single row. In both suburbs the concept, and commodities, of Wellbeing have been translated into creative shop headlines: 'Revitalise', 'Spinal Health', 'Lifestyle and Maternity', 'Revival Health' and 'Your Health' are illustrations. In both places Deli style cafes are close by, and in each main road organic fresh food products flourish. And in both locations Wellbeing services were observed to operate in clusters emerging as complex network organisations. As such the service clusters supplied regular meeting point hubs for various 'healthy lifestyle' groups: such as, walking seniors, all age cyclists, green gym attendees and multiple personal trainer followers, each seemingly with their own distinct informal social organisation and regular patterns of contact.

\section{DISCUSSION AND ANALYSIS}

For all the similarities between locations 11000 miles apart there are too obvious differences. The Australian proportion of frontline agencies is substantially larger: $34 \%: 13 \%$ of the 160 agencies identified in the two high streets examined. So too is that of exclusively private shops and service outlets in the Health and Wellbeing sector at $83 \%$ (n:24) to $33 \%(n: 3)$. Table 1 provides the profiles. Only the UK version has social enterprises: one formed as a voluntary association by disabled people and carers and the other an evangelical Christian charity offering support services through 'care, compassion, community'. In the Hampshire example too, there are more instances of the public National Health Service being cited compared with the (almost completely absent) Medicare alternative in the Melbourne district - at the opticians, dentists, community pharmacists and respite care centre. Integration is more apparent as a result, with the specialised nature of the East Brighton offerings suggesting enhanced direct popular access but also service fragmentation, particularly in the absence of registered patient lists and electronic record transfers.

Table 1. Profile of local shops and service outlets.

\begin{tabular}{|c|c|c|}
\hline Sector & $\begin{array}{c}\text { High Street, } \\
\text { Bishops Waltham }(\mathbf{n = 7 2}) \\
(\mathbf{\%})\end{array}$ & $\begin{array}{c}\text { Bay Street, East Brighton (n=88) } \\
\mathbf{( \% )}\end{array}$ \\
\hline Health and Wellbeing & $\mathbf{9 ( 1 3 \% )}$ & $\mathbf{3 0 ~ ( 3 4 \% )}$ \\
\hline Including: & & 10 \\
\hline Holistic health centres & 1 & 4 \\
\hline Community pharmacies & 2 & 7 \\
\hline Specialist clinics & 3 & 0 \\
\hline Social enterprises & 2 & \\
\hline
\end{tabular}


(Table 1) contd.....

\begin{tabular}{|c|c|c|}
\hline Sector & $\begin{array}{c}\text { High Street, } \\
\text { Bishops Waltham }(\mathbf{n = 7 2}) \\
(\%)\end{array}$ & $\begin{array}{c}\text { Bay Street, East Brighton (n=88) } \\
(\%)\end{array}$ \\
\hline Hospitality & $\mathbf{1 5 ( 2 1 \% )}$ & $\mathbf{2 1}(\mathbf{2 4 \% )}$ \\
\hline Significant Others & & 3 \\
\hline Including: & 7 & 4 \\
\hline Estate agents & 7 & 7 \\
\hline Beauticians/Hairdressers & 4 & \\
\hline Fashions & & \\
\hline
\end{tabular}

The perspectives and perceptions of local medical school interviewees in the two countries also appear to be quite different. In Australia the common view of respondents was that 'these things have nothing to do with us'. Their 'Wellbeing' branded services were typically termed 'Hokum Pokum' and 'Crazy Medicine' by two GP academics, and seen as lacking any substantive evidence base. Both, however, felt the increase had heightened competition, in terms of marketing their own services, and an increased awareness of business income. One actually talked of assessing the capacity to pay as influential criteria in GPs' selection of patients to treat, when faced with a full waiting room. The separation of general medical services from the new Wellbeing services, accordingly, did seem to have some spill-over despite the apparent separation.

In Bishops Waltham the situation was different. In interviews the doctors talked of their responsibility to signpost 'informed' patients, and some provided shortlists of independent allied health professionals and complementary therapists, plus information sheets on local social enterprises. Their perspectives were framed by the experience of commissioning health and health care over the past two decades, and by the explicit recognition of the longitudinal role of GPs in personal care. This 'cradle to the grave' view was missing in Melbourne, where interviewees stated that more choice was leading to more one off GP appointments, more shifts between surgeries and less relationship based care . One said 'We don't understand here what is so special about GPs - why do the British always look up to them?' In East Brighton each agency had separate notes, administrative processes and profit-and-loss balance sheets.

On Bayside, the notion of integrated care was only applied to the internal workings of hospitals, in which public confidence and funding was seen to be high. Yet in Melbourne, integration of alternative therapeutic services on the high street was often observed, with personal trainers sometimes seen to be acting as coordinators of referrals and recommendations for a network of healers and counsellors; and physiologists underpinning personal Wellness regimes with expert advice on a range of nutritional and exercise interventions. Through such developments a novel understanding of Wellbeing was beginning to emerge. Unlike their UK counterparts some of the Australian doctors saw the growth of alternative outlets as one which would in future be accepted because it was part of a collective drive for what they termed variously 'self-improvement', 'vanity and identity', 'competitive edge' and 'achievement'. These terms were very different to the Winchester District references to the possible 'prevention' and 'diversion' (from secondary care) benefits of the new social and commercial enterprises.

In both Winchester and Melbourne interviewees shared a common concern regarding the regulation of the expanding Health and Wellbeing sector, and were uncertain about the future contribution of public health professionals in respect of monitoring and quality assurance. In East Brighton, one proprietor said he expected contacts from the licensing and public health departments 'perhaps once in a lifetime', while in Winchester a local council officer emphasised that Wellbeing began and ended with the provision of paid work ' even if that means more digital gaming and fast food outlets.' Such quotes suggest that the interviewee concerns may be well founded. Together they point to a pressing need to safeguard public health by responding decisively to the speed of new cross-sectoral developments at the frontline. For the new independent agencies to contribute to a rebirth of primary health care it is especially important that they do not undermine the public service organisations on which public health progress has previously relied.

\section{FUTURE RESEARCH AGENDA}

The concerns cited above help to scope the subject area and issues which require new knowledge production and exchange for a sector that is growing rapidly, particularly as the idea of place-based health systems takes hold [21]. The expansion of the Wellbeing brand name is closely associated in Western countries with governments' desire to promote increased innovation and diversity in service provisions for economic growth purposes, as a response to the takeover by Asian countries of industrial production and manufacturing roles. In this context while the micro case studies described 
in this article have all too obvious limitations they do suggest that the principles of Alma Ata have a renewed meaning and relevance in helping to set the research agenda arising from the emergent mixed economy of Wellbeing practices.

Accordingly, drawing on the threefold framework of WHO criteria for primary health care used in the data capture, the following questions are identified and indicated as research priorities from our data analysis.

\section{A. Stakeholder Participation}

- What are the regulatory requirements for effective Wellbeing services? (And how can policies for these be effectively implemented by local authorities?)

- Which models of community governance can be successfully applied in a mixed economy of diverse Wellbeing services at the frontline of primary health care?

B. Inter-sectoral Collaboration

- How can relationships between general medical services and Wellbeing service outlets promote (and prevent) improvements in public health? (And both be supported by further and higher education units?).

- Where are the main opportunities for positive collaboration between statutory health agencies and informal social organisations and new communities of Wellbeing?

C. Equity (of Access)

- What are the risks and benefits for health care investment arising from the increased levels of private and copayments for frontline Wellbeing services?

- Can commercial and social enterprises for high street Wellbeing services co-exist, over time, in the interests of both consumers and patients?

In the responses to such questions as these lies the bigger answer to the question of whether or not the emergent profile of diverse Wellbeing outlets helps revive the aspirations of the World Health Organisation and its followers [13, 22] for primary health care. Are they overall a good thing or not? In the UK recent reports on 'Health in the High Street' have concentrated on the negative impact of such as fast food chains, sun tanning salons and pay-day loan merchants [23, 24]. In Melbourne the emphasis has been on the positives, believing the downside of evidential shortfalls for Wellbeing interventions is more than made up for by the upturn in health awareness, personal responsibility and opportunities for cultural absorption of new immigrants [25]. In 1978 at Alma Ata, the WHO Annual Assembly looked to the values and practices of primary health care to underpin 'a state of complete physical, mental and social well-being and not merely the absence of disease or infirmity’ [11]. If Australia is right, by 2018 it may be able to do so again.

\section{CONFLICT OF INTEREST}

The author confirms that this article content has no conflict of interest.

\section{ACKNOWLEDGEMENTS}

The project was supported by grants from Primary Care Matters and the Granger Cottman Endowment Fund.

\section{REFERENCES}

[1] Garcia-Pena C, Duran L, Munoz O, Vazquez F, Eds. Family medicine at the dawn of the $21^{\text {st }}$ century: themes and arguments. D.F., Mexico: Comision Americana Medico Social 2005.

[2] Naccarella L, Buchan J, Newton B, Brooks P. Role of Australian primary healthcare organisations (PHCOs) in primary healthcare (PHC) workforce planning: lessons from abroad. Aust Health Rev 2011; 35(3): 262-6. [http://dx.doi.org/10.1071/AH10934] [PMID: 21871184]

[3] Atun R. What are the advantages and disadvantages of restructuring a health care system to be more focused on primary care services?. Copenhagen: WHO Regional Office of Europe 2004.

[4] Meads G. The organisation of primary care in Europe: Part 1 trends- Position Paper. European Forum for Primary Care. Qual Prime Care, 17(2): 133-43 2009.

[5] Hall J. Incremental change in the Australian health care system. Health Aff (Millwood) 1999; 18(3): 95-110. 
[http://dx.doi.org/10.1377/hlthaff.18.3.95] [PMID: 10388206]

[6] Meads G, Lees A, Russell G. Community governance in primary care: towards an ideal type. Int J Health Plann Manage 2016, May 27. [Epub ahead of print]

[PMID: 27230589] [http://dx.doi.org/10.1002/hpm.2360]

[7] Department of Health. The Health of the Nation: a strategy for health in England. Series: Cm 1986, London: HMSO, 1991.

[8] Department of Health. NHS five year forward view. London: DoH 2014.

[9] Department of Health. NHS Planning Guidance 2015/ 2016. London: DoH 2015.

[10] Commission on Place Based Health. Get well soon. London: New Local Government Network /Collaborate CIC 2015.

[11] International Conference on Primary Health Care. Alma-Ata, USSR, 6-12, WHO Declaration, 1978.

[12] Bryman A. Social research methods. Oxford: Oxford University Press 2012.

[13] Primary Health Care: Now More than Ever Annual Report. Geneva: World Health Organisation 2008.

[14] MacDonald JJ. Primary health care: medicine in its place. London: Routledge 1992.

[15] Ferlie E, Fitzgerald L, McGivern G. The networks in health care: a comparative study of their impact, management and performance. London: National Institute of Health Research, Service Delivery and Organisation Research Programme 2007.

[16] Meads G. Primary care in the twenty first century. Abingdon, England: Radcliffe Press 2006.

[17] Hart J. Annual report: Chair's address. Winchester, UK: Winchester Basics Bank 2015.

[18] Carmona M. London's local high streets: the problems, potential and complexities of mixed street corridors. Prog Plann 2015; 100: 1-84. [http://dx.doi.org/10.1016/j.progress.2014.03.001]

[19] Campbell S, James EL, Stacey FG, Bowman J, Chapman K, Kelly B. A mixed-method examination of food marketing directed towards children in Australian supermarkets. Health Promot Int 2014; 29(2): 267-77.

[http://dx.doi.org/10.1093/heapro/das060] [PMID: 23154998]

[20] Fraser LK, Clarke GP, Cade JE, Edwards KL. Fast food and obesity: a spatial analysis in a large United Kingdom population of children aged 13-15. Am J Prev Med 2012; 42(5): e77-85.

[http://dx.doi.org/10.1016/j.amepre.2012.02.007] [PMID: 22516506]

[21] Ham C, Alderwick H. Place-based systems of care. London: Kings Fund Foundation 2015.

[22] Addicott R. Social enterprise in health care. London: Kings Fund Centre 2011.

[23] Royal Society for Public Health. Health on the High Street. London: RSPH reports 2015.

[24] NHS Confederation. Health on the high street: rethinking the role of community pharmacy. Pharmacy and public health task force report Birmingham, UK, NHS Confederation 2013.

[25] Mason C, Barraket J, Friel S, O’Rourke K, Stenta C-P. Social innovation for the promotion of health equity. Health Promot Int 2015; 30(Suppl. 2): ii116-25.

[http://dx.doi.org/10.1093/heapro/dav076] [PMID: 26420807]

(C) Geoffrey Meads; Licensee Bentham Open

This is an open access article licensed under the terms of the Creative Commons Attribution-Non-Commercial 4.0 International Public License (CC BY-NC 4.0) (https://creativecommons.org/licenses/by-nc/4.0/legalcode), which permits unrestricted, non-commercial use, distribution and reproduction in any medium, provided the work is properly cited. 